\title{
Estimation of the seismic resistance heritage buildings by dynamic testing of their structural parts
}

\author{
I. Iskhakov \& Y. Ribakov \\ Department of Civil Engineering, \\ Ariel University Centre of Samaria, Israel
}

\begin{abstract}
Dynamic testing of full-scale heritage buildings is one of the ways to estimate their seismic resistance. However, this method is rather seldom used, because it is a time- and cost consuming procedure, and it may yield nonlinear deformations, damages in structural elements, which is unacceptable for heritage buildings. Dynamic testing of a relatively small part of a multi-storey building (having the same structural scheme) is one of the possible ways for solution of the above described problem. The reliability of the experimental results, obtained for the structural part, should be verified (at least once) by comparison to those from dynamic tests of a full-scale building. Because this method is problematic for a heritage building, the authors have verified the proposed technique on a usual full-scale multi-storey building and its structural part. A three-storey structural part was tested and the results were compared to those obtained by dynamic vibration testing of the full-scale 11-storey building. It was shown that, if the dynamic parameters of both structures are close, it is possible to obtain the seismic loads acting on the real building, using the impulse forces applied to the structural part. This approach may also be successfully used for the estimation of seismic resistance of real heritage buildings. If a heritage building is located in a seismic zone and according to the experimental data it has low seismic resistance, it is possible to use a base isolation system for improving its seismic response. It is shown in this study that the design of a base isolation system for a full-scale building can be carried out according to experimental results obtained for a structural part of the building.
\end{abstract}

Keywords: dynamic testing, full-scale multi-storey building, structural part, estimation of seismic resistance, base isolation. 


\section{Introduction}

Heritage buildings in certain cases do not satisfy the modern code requirements for the seismic zone in which they were constructed. Seismic resistance of a building can be estimated by full-scale tests, but that is uneconomical and not always possible for heritage buildings. Another way is to test a scale model of a structure. Matteis et al. [9] studied the dynamic features of the Fossanova Cathedral by ambient vibration tests and numerical analyses. Later experimental testing of three models on the shaking table (a mosque, a cathedral and a church) and ambient vibration testing of prototype structures were carried out [13]. The tests were aimed at studying the seismic resistance of historical buildings.

An alternative approach is to subject a full-scale building to testing under vibration, or impulse loading. It can provide valuable information about the dynamic parameters of buildings - information that can be used to calibrate theoretical models, develop modelling techniques, and verify theoretically predicted damage. However, this method is unacceptable for heritage buildings because such tests may cause essential damage to the building.

Dynamical testing of full-scale parts of buildings provides information about the real dynamical parameters of the whole system, such as natural vibration periods, vibration modes and damping ratios [10]. One of the advantages of this approach is that it makes it possible to estimate nonlinear structural behaviour of a full scale building. This idea can be applied to multi-storey heritage buildings. For this reason a full-scale part of the building should be constructed and tested. An essential condition is that the tested part should have the same structural scheme like the investigated building. Because the tested structural part doesn't belong to the heritage building, it is possible to apply all modern testing methods described below in order to investigate its dynamic characteristics.

Fajfar and Godec [3] obtained periods and free vibration mode shapes using numerical analysis and full-scale tests on three actual multi-storey RC buildings. They have reported that the dynamical characteristics, obtained from the free vibration tests for a 20-storey shear wall building, agreed with a mathematical model. As shown by the experimental results for a 10-storey building, good correlation of the results depended upon allowance being made for the flexibility of the floor slabs in their plane (the 10-storey structure could be treated as a fragment of the 20-storey one). The third building was a 12-storey frame with infill walls. The influence of walls was included in the theoretical model. The 12 -storey structure could be also treated as a full-scale fragment of the 20-storey frame.

Kaminosono et al. [4] tested a full-scale 7-storey RC structure. The objectives of this study were obtaining the behaviour of the structure, comparing the test results with analytical dynamic response analysis. The experimental study consisted of vibration, static loading and pseudo-dynamic tests. During the last test the structure was damaged. In order to perform further tests, the damaged 7storey structure has been repaired and non-structural elements were installed [5]. The seismic-resistance of non-structural elements was verified in further pseudodynamic tests. A method for retrofitting of similar existing structures, damaged 
by earthquakes, was developed. Results of other experimental studies of fullscale structures were reported in [6-8] and others.

Another recently developed method is testing a one-storey part of a real building, subjected to ground motion, reproduced by a shaking table, and a force, applied at the top of the tested specimen by an active controlled actuator [12]. The actuator reproduces the dynamic force that would be transmitted by the above floors of the building to its first storey under the same ground motion. The force value is obtained online by numerical simulation of the building's response taking into account the actuator delay and dynamics compensation, and it is applied to the tested one-storey specimen.

By testing a full-scale part of a building, it is possible to determine its nonlinear dynamical parameters. The heritage building may be expected to have the same parameters. However, the ultimate aim is to minimize the inelastic response of the building. This may be done by implementing a base isolation system with characteristics, chosen so that the whole system (building and base isolation) will have the required dynamical parameters. An important advantage of base isolation in retrofitting of heritage buildings is that it doesn't change the architectural view of the building and the structural scheme of the superstructure.

Many multi-storey buildings in Israel and the Mediterranean area that were constructed more than 40 years ago have a framed structural scheme. Part of them belongs to heritage architecture.

In this study a full-scale fixed-base three-storey structure - a part of an 11storey RC building - was tested and its nonlinear response was determined. Based on the obtained results, a base isolation system was designed using the proposed approach. The results, obtained for a structural part, were verified for the real building.

\section{Motivation and aims for dynamic testing structural parts of multi-storey buildings}

Results of structural part dynamic testing can be used for prognosis of damage progress in full-scale buildings. It allows preventing of nonlinear deformations, cracking and estimation of buildings ability to withstand seismic loads. The proposed method may be also used for evaluation of seismic resistance of multistorey buildings for using them in seismic zones with higher PGA than that, for which they were designed. It can be also used to study behaviour of structural elements joints under strong dynamic loading. Dynamic testing of a structural part of a building is one of the possible ways for solving this problem. It avoids a complicated process of full-scale buildings dynamic scaling, aimed to reduce the dimensions of the tested structure.

This work is aimed at verification of such method by comparing the results obtained by testing a structural part to those of a full-scale building. For this reason a full-scale 11-storey building and its three-storey structural part were tested. Additionally, effectiveness of using base isolation systems, designed for structural part, in full-scale building was examined. 


\section{Program of full-scale building experimental investigation}

As it was mentioned above, this paper is focused on full scale testing of an RC 11 -storey building and its three-storey part. The experimental program was aimed at structural dynamic behaviour examination of such type of buildings for seismic zones with PGA $0.1 \mathrm{~g}, 0.15 \mathrm{~g}$ and $0.3 \mathrm{~g}$. An idea of using dynamic parameters of a structural part for design of the building was examined. An additional problem was selecting the structural part so that its dynamic behaviour would be close to that of the real structure (at least, for the dominant vibration mode). For such multi-storey buildings (in our case for the 11-storey building) contribution of the first three modes is usually more than $90 \%$ of the total dynamic response. In this case, according to the requirements of modern seismic codes $[1,2]$, influence of higher modes can be neglected in the design procedure. Based on this assumption, a three-storey structural part of the 11-storey building was selected. Moreover, the structural scheme of the building and of its part to be tested should be the same. The main structural joints, foundations and the soil conditions of the building and of its structural part should be identical. In order to obtain similar logarithmic decrements for the building and for its structural part free vibration tests are used. It is logically to expect that if all the above mentioned conditions are fulfilled, the dynamic behaviour of both structures will be similar and yield analogous structural damages.

Testing a structural part allows a unique possibility to investigate the influence of live loads on building's dynamic parameters by applying additional gravitation (static) loading. Carrying out similar tests on full-scale buildings is very difficult, but the effect of this loading can be taken into account for design of real multi-storey buildings. It is shown that based on the results, obtained from testing the structural part, recommendations, regarding suitability of the building for a seismic zone with known seismic activity, can be formulated.

\section{Main experimental results}

\subsection{Three-storey structural part}

The tests were carried out on a three-storey part of an 11-storey pre-cast RC building under construction, as shown in Figure $1[10,11]$. The building had a beamless frame structure, and its part consisted of two columns and three slabs (Figure 2). Impulse loads were applied at the roof level in the plane of the frame. The impulse was provided by instantaneous application of the load by a guy cable (Figure 3). The tests were carried out in steps. In the first step, recording of the micro-seismic vibration of the frame was followed by impulse forces of 30 and $70 \mathrm{kN}$ and applying a vertical static load of $3.84 \mathrm{kN} / \mathrm{m}^{2}$ on the slabs. In the second step, the statically-loaded frame was subjected to impulse forces of 30 , 70 and $106 \mathrm{kN}$. The peak horizontal roof displacements of the frame were 45, 110 and $175 \mathrm{~mm}$, respectively. In the third step, the statically loaded frame was subjected to forces of 34,77 and $110 \mathrm{kN}$. In the last case, the peak horizontal 
roof displacement was $200 \mathrm{~mm}$. Cracks developed in the slabs under the $77 \mathrm{kN}$ load and in the columns under the $110 \mathrm{kN}$ load.

Damping ratio of the first vibration mode was determined using a logarithmic decrement. The experimentally obtained damping was used for further analysis of the structure. The micro-seismic records revealed 3 modes of vibration with the following periods: $\mathrm{T}_{1}=0.6 \mathrm{~s}, \mathrm{~T}_{2}=0.16 \mathrm{~s}, \mathrm{~T}_{3}=0.06 \mathrm{~s}$. The following periods were recorded under $30 \mathrm{kN}: \mathrm{T}_{1}=0.8 \mathrm{~s}, \mathrm{~T}_{2}=0.16 \mathrm{~s}$. On transition from 30 to 70 $\mathrm{kN}$, the periods of the first and second modes increased by $20 \%$. The third mode was recorded with a period of $0.11 \mathrm{~s}$. Under $77 \mathrm{kN}$, the periods were $\mathrm{T}_{1}=1.35 \mathrm{~s}$ and $\mathrm{T}_{2}=0.3 \mathrm{~s}$ (Figure 4). The natural periods of the frame are clearly seen to depend on the impulse load, which indicates that nonlinear vibrations have developed.

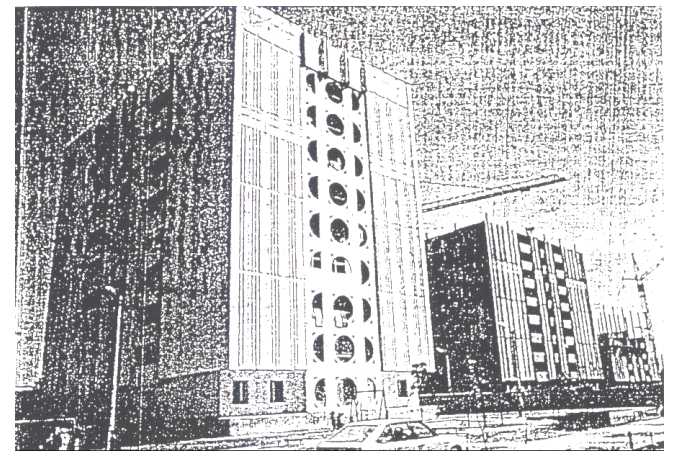

(a)

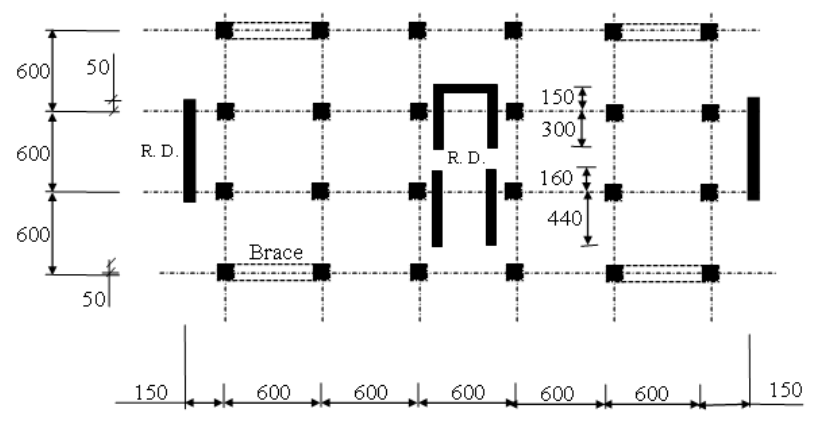

(b)

Figure 1: $\quad$ The 11-storey building: (a) general view, (b) typical floor plan.

Figure 5 shows the experimentally obtained relation between the maximum amplitude of horizontal displacement of the frame and the intensity of the applied dynamical loads, which ranged from 30 to $110 \mathrm{kN}$. Nonlinear vibration occurred when the impulse load was $70 \mathrm{kN}$ (see Figure 4). The roof accelerations were also recorded. Under the $70 \mathrm{kN}$ load, the acceleration of the fragment was 
$0.35 \mathrm{~g}$, which is equivalent to a strong earthquake. Thus, under impulse forces ranging between 70 and $110 \mathrm{kN}$, the frame behaved as a geometrically and physically nonlinear system. The damping ratio of the frame was 0.1 .

\subsection{1-storey full-scale building}

The full-scale structure has been submitted to dynamic loads in order to determine experimentally the building's dynamic parameters under microseismic oscillations and vibration resonance actions. The tests were also aimed at verification of dynamic parameters of the building, obtained from impulse testing of a structural three-storey part.

The vibration was achieved using a machine consisting of five blocks, actuated by two electric motors, working simultaneously. For recording the building's dynamic parameters 11 accelerometers were used. Before the tests the accelerometers were verified on a vibration table. After the test the building was inspected and all damages were described and documented [11].

Before the vibration test, the natural vibration periods of the building were determined applying a $1 \times 1 \times 1.5 \mathrm{~m}$ concrete block impact at the upper floor. The tests were carried out in phases. In each phase, the unbalanced masses of the
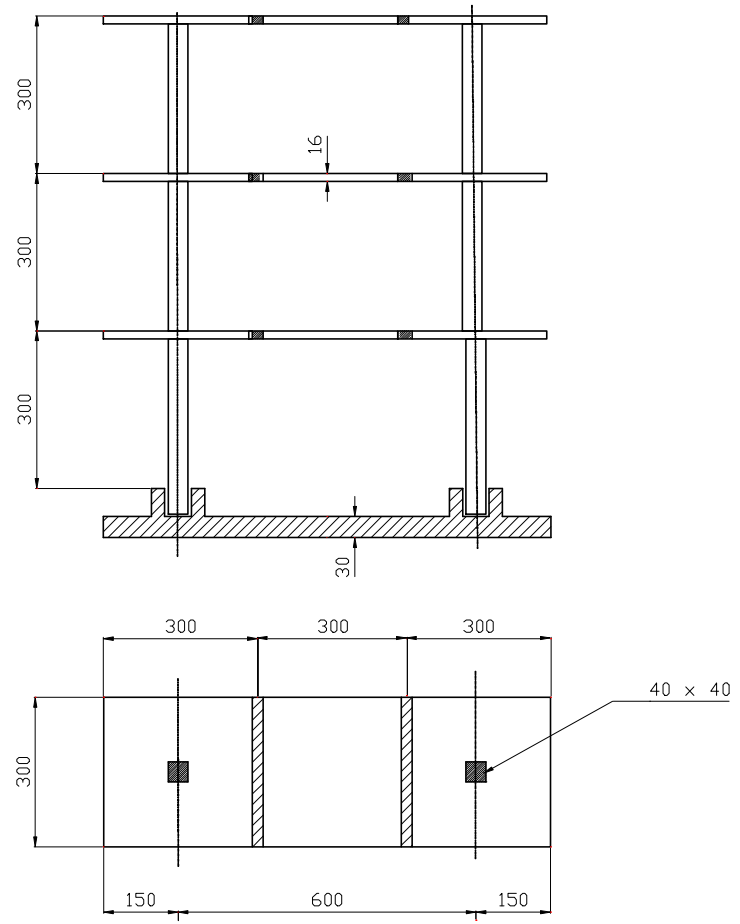

Figure 2: $\quad$ Structural scheme of the tested part. 


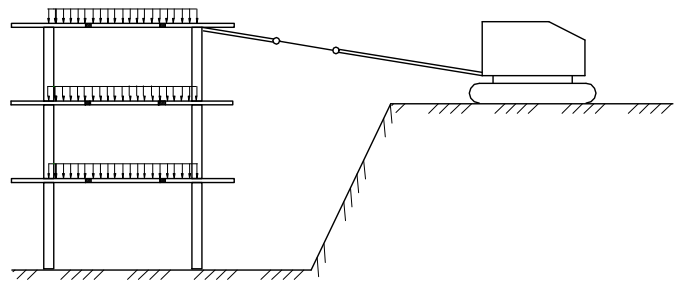

Figure 3: Application of an impulse to the building part.

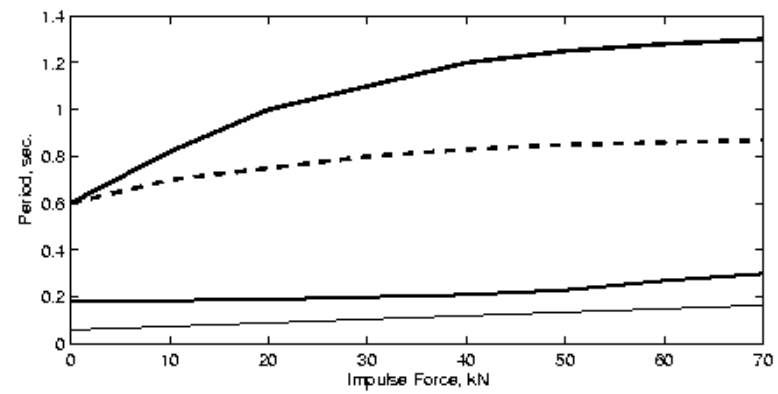

$$
\begin{aligned}
& \text { - - - - Londed Frame. lhitodely } \\
& \text { Loaded Frame. (hilode } 2 \text { ) } \\
& \text { Loaded Frame. lihade } 3
\end{aligned}
$$

Figure 4: $\quad$ Experimentally obtained vibration periods.

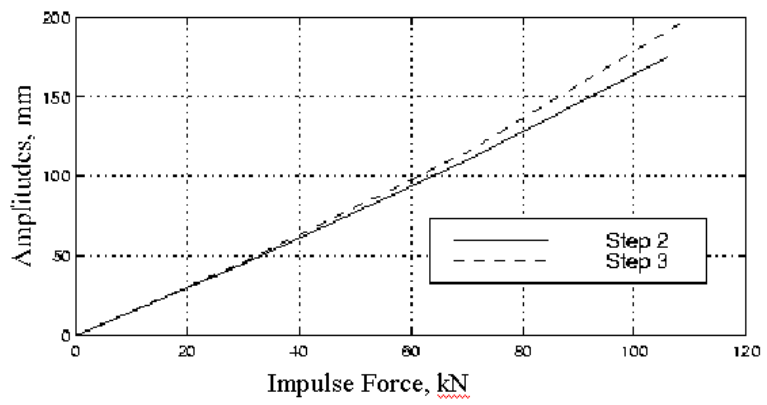

Figure 5: $\quad$ Experimentally obtained vibration amplitudes.

vibration machine were increased corresponding to the required equivalent PGA. After each phase the building and its joints were inspected, including cracks development, damages caused to structural elements, etc.

According to the experimental results, the building's dominant vibration periods were $0.585 \mathrm{~s}$ in the transverse direction and $0.615 \mathrm{~s}$ in the longitudinal one, respectively. In the first phase the unbalanced mass was $1440 \mathrm{~kg}$ and the obtained oscillation period $0.65 \mathrm{~s}$. The building's peak roof displacement was 4.5 
$\mathrm{mm}$. After the first phase the unbalanced mass was increased to $2720 \mathrm{~kg}$, $3240 \mathrm{~kg}$ and $3280 \mathrm{~kg}$ [11]. The maximum dominant vibration period was $0.72 \mathrm{~s}$ in the transverse direction. Its final value (obtained from the impact test performed after the experiments) was $0.70 \mathrm{~s}$. The increase in the transverse direction vibration period from $0.585 \mathrm{~s}$ to $0.72 \mathrm{~s}$ shows, that some of the structure's rigidity was lost due to cracking and local damages.

\section{Base isolation system for structural parts}

Increase in vibration periods of a three-storey structural part was an evidence of nonlinear deformations in the frame. To reduce the nonlinear behaviour, a base isolation system (BIS) was used. It was designed so that the displacement of the roof relative to the first storey column bottom would be less than or equal to that of the fixed-base structure (as obtained in the tests). It was also expected to reduce the energy dissipated in the structural elements during their nonlinear behaviour. Numerical simulation of the structural part with BIS showed that the behaviour of the isolated structure was linear and excluded its cracking [10].

The results of the numerical analysis and the corresponding experimental data are given in Figure 6. The experiments showed that as the impulse load was increased, the displacements increased nonlinearly. The disagreement between these data and the theoretically obtained results was less than $10 \%$. The BIS afforded a reduction in inter-storey drifts without increasing roof displacement. It reduced the nonlinearity of the deformation, thereby lowering the risk of damage and failure of the elements.

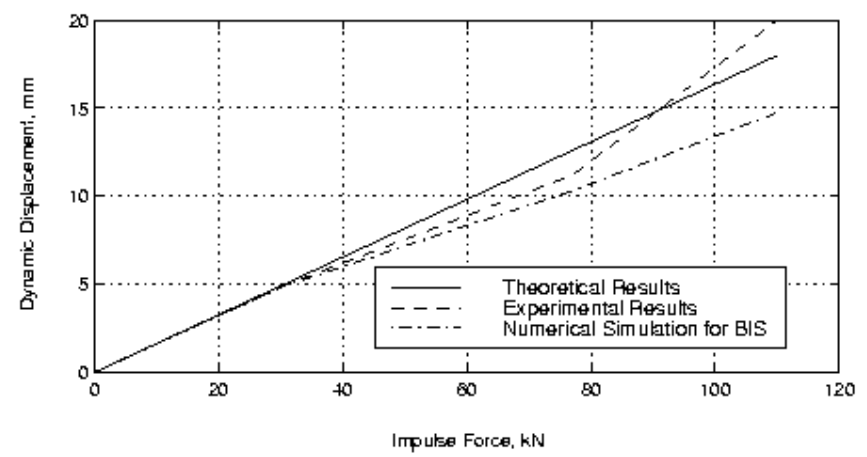

Figure 6: Displacements of the structural part.

The goal of base isolation of the real 11-storey building was to keep the structural peak response to earthquakes with PGA of $0.3 \mathrm{~g}$ similar to that of a fixed-base structure under the vibration loads with PGA of $0.15 \mathrm{~g}$ (measured experimentally). Based on parametric study [11], it was concluded, that for the structure the above mentioned aim is successfully achieved by using a BIS with a natural vibration period of $1.4 \mathrm{~s}$. This is because the dominant vibration period of a structure with BIS mainly depends on the characteristics of the isolation, 
whereas the superstructure contributes less to the vibration period of the isolated building. The vibration period of an 11-storey building corresponds to that of a three-storey structural part with addition of gravitation loading [10]. Such method of using dynamic characteristics of a structural part for design of BIS for a full scale building, in our opinion, will be effective for framed structures up to 10-12 stories.

The response of the investigated full-scale structure to three selected earthquakes scaled to PGA of $0.3 \mathrm{~g}$ has been obtained for the following study cases: 1) a fixed base structure; 2) a base isolated structure with vibration period of $1.4 \mathrm{~s}$. The peak response of the structure is presented in Table 1 .

Table 1: $\quad$ Peak response of the 11-storey building (base isolated/fixed base).

\begin{tabular}{|c|c|c|}
\hline Seismic motion & Roof displacement, $\mathrm{cm}$ & Base shear, $\mathrm{kN}$ \\
\hline El-Centro & $0.7 / 2.52$ & $3690 / 6770$ \\
\hline Eilat & $0.13 / 2.39$ & $3700 / 6310$ \\
\hline Kobe & $0.13 / 2.17$ & $3650 / 7020$ \\
\hline
\end{tabular}

Following the table, using the BIS with the proposed vibration period yields significant reduction of the maximum displacements and base shear forces. Hence, the BIS, selected according to structural dynamic parameters, obtained from experimental investigation of a three-storey structural part with addition of gravitation loading, efficiently works in a full-scale 11-storey building.

\section{Discussion and conclusions}

Impulse testing of a three-storey structural part was carried out and the results were compared to those of dynamic vibration testing of the full-scale 11-storey $\mathrm{RC}$ building. It was shown that, if the dynamic parameters of both structures are close, it is possible to obtain the seismic loads, acting on the real building, using the impulse forces, applied to the structural part. Additionally, effectiveness of a base isolation for a full-scale building, designed using the results of structural part impulse testing, was examined. Using the BIS with the proposed vibration period yields significant reduction of the maximum displacements and base shear forces.

It can be concluded that dynamic testing of a small part of a heritage multistorey building is one of the possible ways for testing real buildings' seismic behaviour. This approach may be successfully used for estimation of seismic resistance of real heritage buildings. It was proved that the BIS, selected according to structural dynamic parameters, obtained from testing the threestorey structural part is effective for the full-scale 11-storey building.

\section{References}

[1] Eurocode 8. (1993) Design provisions for earthquake resistance of structures. Part 1-3: General rules. 
[2] IC 413 (1998) Design provisions for earthquake resistance of structures. The standards Institution of Israel.

[3] P. Fajfar and M.A. Godec "Comparison of Numerical Analyses and FullScale Tests for Free Vibrations of Three Reinforced Concrete Buildings," Institute of Structural and Earthquake Engineering, Yugoslavia, 1982.

[4] Kaminosono, T. et al. The full-scale seismic experiment of a 7-storey RC building, Part 1: Outline of test results. 6-th Japan Earthquake Engineering Symposium - 1982, Japan, Tokyo, 1982, pp. 865-872.

[5] Okamoto, S. et al. A Progress Report on the Full-Scale seismic Experiment of a 7-Storey RC Building-Part 2. 14th Joint Panel Conf. of the U.S.-Japan Cooperative Program in Natural Resources, 1983, pp. 457-475.

[6] Bae, G.H., Suzuki, Y. Experimental Identification of Full-Scale Specimen Frame by Using Earthquake Response Generator System. Second World Conf. on Structural Control, J. Wiley \& Sons, 1999, pp. 2289-2296.

[7] Negro, P. and Molina, F. J. Bi-directional Pseudo-dynamic Tests on a 3Storey Full-Scale Composite Asymmetric Building. The 5th Management Panel on Collaboration Research Activities about Building Structural Engineering between JRC-ISIS \& JBRI, Tsukuba, Japan, 2001, pp. 49-69.

[8] Paultre, P. et al. Damage Detection by Repeated Forced-Vibration Testing on a Two-Storey HPC Building. The 12-th European Conf. on Earthquake Engineering. Elsevier Science Ltd., 2002, Paper Reference 565.

[9] G. De Matteis, I. Langone, F. Colanzi, A. Eboli and F.M. Mazzolani. Numerical evaluation of the seismic response of the Fossanova cathedral based on experimental dynamic identification, Structural Engineering, Mechanics and Computation 3, A. Zingoni (ed.), pp. 364-369.

[10] I. Iskhakov and Y. Ribakov "Selection of Base Isolation System Properties Using a Three-Storey Structural Part Impulse Tests", European Earthquake Engineering, XIX (1), 38-42, 2005.

[11] I. Iskhakov and Y. Ribakov "Full-Scale Dynamical Testing of an 11-Storey $R C$ Building and Interpretation of the Results from the Seismic-Resistance Viewpoint," Structures Under Shock and Impact VI, Ed. N. Johns and C.A. Brebbia, WIT Press, Southampton, Boston, 2000, pp. 331-338.

[12] M. Ahmadizadeh, G. Mosqueda and A.M. Reinhorn "Compensation of Actuator Delay and Dynamics for Real-Time Hybrid Structural Simulation", Earthquake Engineering and Structural Dynamics, 37, 21-42, 2008.

[13] Earthquake Protection of Historical Buildings by Reversible Mixed Technologies PROHITECH, Internet recourse http://www.prohitech.com/ documents/meetings/minutes_of_the_byzantine_church_meeting_july_200 8.pdf 